\title{
Correction of Hydrological and Oceanic Effects from GRACE Data by Combination of the Steric Sea Level, Altimetry Data and GLDAS Model
}

\author{
Farzam FATOLAZADEH, Behzad VOOSOGHI, \\ and Mehdi RAOOFIAN NAEENI
}

Faculty of Geodesy and Geomatics Engineering,

K.N. Toosi University of Technology, Tehran, Iran;

e-mails: ffatollahzadeh@mail.kntu.ac.ir, vosoghi@kntu.ac.ir, mraoofian@kntu.ac.ir (corresponding author)

\begin{abstract}
In this study, a scheme to estimate oceanic and hydrological effects in the GRACE (Gravity Recovery and Climate Experiment) data is presented. The aim is to reveal tectonic signals for the case of the Sumatra earthquake on 26 December 2004. The variations of hydrological and oceanic effects are estimated with the aid of data set of GRACE, altimetry, World Ocean Atlas, and the GLDAS model for a period of January 2003 to December 2006. The time series of computed gravity changes over Sumatra region show some correlations to the deformation resulting from the earthquake occurred in December 2004. The maximum and minimum impacts of hydrological and oceanic effects on gravity changes are about $3 \mu \mathrm{Gal}$ in radial direction and $-5 \mu \mathrm{Gal}$ in northward direction. The maximum and minimum amounts of gravitational gradient changes after the correction are 0.2 and $-0.25 \mathrm{mE}$, which indicates the significant influences of hydrological and oceanic sources on the desired signal.
\end{abstract}

Key words: hydrological and oceanic effects, GRACE data, World Ocean Atlas, GLDAS model, gravitational gradient changes.

Ownership: Institute of Geophysics, Polish Academy of Sciences;

(C) 2016 Fatolazadeh et al. This is an open access article distributed under the Creative Commons Attribution-NonCommercial-NoDerivs license, http://creativecommons.org/licenses/by-nc-nd/3.0/. 


\section{INTRODUCTION}

Satellite measurements of time-variable gravity field are a new data type, capable of modeling and detecting global mass transfer within the Earth. Such a global mass redistribution may be due to large exchange of water reservoir in the oceans and lands and may lead to significant changes of the Earth's gravity field which can be well detected by gravimetric satellite. The regional mass transfer such as localized tectonic processes due to earthquake, volcano and Tsunami, however, have an indicative influence on gravity fields that may be sensed by space observations (Han et al. 2013, Bao et al. 2005). This subject, in its present form, began with the launch of GRACE mission (the Gravity Recovery and Climate Experiments) (Tapley et al. 2004). The GRACE mission provides a useful apparatus to study the time-variation of the gravity field of the Earth. GRACE is able to monitor changes in a total water supply from the land surface to the base of the deepest aquifer (surface water, soil moisture, groundwater, snow) (Tourian et al. 2015, Fatolazadeh et al. 2016).

Numerous studies published in the recent years have shown that GRACE can offer useful constraints on ocean mass change (e.g., Lombard et al. 2007), mass balance of the ice sheets (e.g., Velicogna and Wahr 2006, Luthcke et al. 2006), terrestrial water storage change (e.g., Tapley et al. 2004, Wahr et al. 2004), polar ice sheet melting (e.g., Velicogna and Wahr 2006), and gravity variations due to localized tectonic processes (e.g., Chen et al. 2007).

A large body of researches devoted to evaluations of hydrological effects in the GRACE data which primarily focused on the use of hydrological models. Rajner et al. (2012) demonstrated that the hydrological effects would change the gravity field of the Earth up to $6 \mu \mathrm{Gal}$ per year in global scale, whereas its local effects may reach to $10 \mu \mathrm{Gal}$ (see also Creutzfeldt et al. 2010). Unfortunately, these models only account the variation of water level in continents and as a result discard the effects due to ocean currents (see, e.g., Feng and Jin 2012). In some cases, hydrological effects have been removed without reference to specific hydrological model, by simply using an averaging scheme (see Chen et al. 2007, Wang et al. 2012).

It should be mentioned that in a similar contributions of this subject (Wang et al. 2012), in order to suppress the hydrological effects, the difference between the averaged gravity field of two years before and after the earthquake is considered (as hydrological free signal), which means that the hydrological effects are assumed to have the same influences on the gravity field before and after the earthquake. However, in this study it is shown that in the aforementioned case, some hydrological effects would remain and may contaminate the desired tectonic signal in observations. 
In this paper, we present an approach for correction of hydrological and oceanic effects in the GRACE observations of level-2 data from period of January 2003 to December 2006 which considers the variations in the water supply from both the oceans and continents. By this way, we could extract the tectonic signal related to Sumatra earthquake occurred in December 2004. To do so, the outputs of the GLDAS model (Global Land Data Assimilation System model) (see Rodell et al. 2004) could be used to account for hydrological effects in lands. For oceanic effects, the difference between altimetry data and World Ocean Atlas (Stephens et al. 2002) model is used which may account for the total oceanic mass variations. The last step is to remove the above effects (hydrological effects in land plus oceanic mass transfer) from the GRACE observations. Thus, the remaining signal in the GRACE data would be due to desired tectonic signal. It should be mentioned that since the GRACE observations of level-2 have been corrected for background ocean model (Lyard et al. 2006), before subtracting the hydrological and oceanic effects, at first, it is necessary that this model be restored in the GRACE monthly solution via a new Ocean Bottom Pressure product (GAD coefficients) (Flechtner 2007).

\section{THEORETICAL BACKGROUND}

The fundamental result of physical geodesy is that the gravitational potential of the Earth satisfies Laplace equation in its exterior boundary, namely (Heiskanen and Moritz 1967):

$$
\nabla^{2} V=0 \quad \text { out of the Earth , }
$$

in which $V$ is the gravitational potential and $\nabla^{2}$ stands for the Laplace operator. In spherical coordinate system with coordinates $\lambda, \varphi$, and $r$, which respectively correspond to longitude, latitude and radial coordinates, and the origin at the center of mass of the Earth (the natural coordinate of the Earth based on its principle moment of inertia), the solution of the above equation can be represented as (Heiskanen and Moritz 1967):

$$
V(\lambda, \varphi, r)=\frac{G M}{r}\left\{1+\sum_{n=2}^{\infty}\left(\frac{R}{r}\right)^{n} \sum_{m=0}^{n}\left[\bar{C}_{m n} \bar{P}_{m n}(\sin \varphi) \cos m \lambda+\bar{S}_{m n} \bar{P}_{m n}(\sin \varphi) \sin m \lambda\right]\right\}
$$

in which $G$ is the universal constant of gravitation, $M$ the total mass of the Earth, $\bar{C}_{n m}$ and $\bar{S}_{n m}$ the non-dimensional Stokes coefficients and $\bar{P}_{n m}(\sin \varphi)$ are associated Legendre polynomial in latitude of degree $n$ and order $m$.

One of the important goals of satellite gravimetry is the determination of the so-called Stokes coefficients up to a maximum degree and orders which mostly depends on the altitude of satellite and its temporal and spatial reso- 
lutions. Three space missions have been dedicated to this matter, which are CHAMP, GRACE, and GOCE missions (Tsoulis and Patlakis 2014). GRACE satellite, launched jointly by NASA and the German Aerospace Center (DLR) in March 2002 (Tapley et al. 2004), consists of two identical satellites in similar orbits, one following the other by about $220 \mathrm{~km}$ and at an altitude of approximately $400 \mathrm{~km}$ above the Earth. The satellites use microwave signal to continuously measure their separation distance to an accuracy of better than 1 micrometer. This observation may be converted to information about gravity field of the Earth.

All the data received from the satellite (raw data) are processed at the Raw Data Center (RDC) to level-0 GRACE data type. At this stage, they are transformed into physically meaningful quantities, such as satellite-tosatellite distances, non-gravitational accelerations, spacecraft attitude, etc., which are the so-called level-1 data that can be used to construct gravity field solution. Since few users have the capability of working with this type of observation, level-2 products are generated at several project-related processing centers (the Center for Space Research at the University of Texas, Geo Forschungs Zentrump in Potsdam, Germany, and the Jet Propulsion Laboratory), and each of these products is made available to users (Wahr et al. 1998). The level-2 gravity products consist of complete sets of spherical harmonic (Stokes) coefficients up to some maximum degree and order (typically 120), averaged over monthly intervals.

Using the GRACE observations of level-1, the gravity field of the Earth could be recovered in terms of aforementioned spherical harmonics which constitute the level-2 data. These coefficients released by temporal resolution of one month. The difference between the monthly index of $\bar{C}_{n m}$ and $\bar{S}_{n m}$ and the average index of $\bar{C}_{n m}$ and $\bar{S}_{n m}$ over definite period of time may be used as an indicator of significant mass change during a specific month.

GRACE can measure the gravity field variations which include any considerable changes occurring in the mass distribution of the Earth, such as changes in the amount of water reservoirs or local mass transfer due to seismic phenomena. Therefore, one may write:

$$
\delta M^{\text {GRACE }}=\delta M^{\text {Hydrology }}+\delta M^{\text {Seismic }}+\delta M^{\text {Oceanic }}+\delta M^{\text {Others }},
$$

where $\delta M^{\mathrm{GRACE}}$ is a total mass variations observed by GRACE, $\delta M^{\text {Hydrology }}$ is a mass variations due to hydrological effects, $\delta M^{\text {Oceanic }}$ is a mass variations due to oceanic effects, $\delta M^{\text {Seismic }}$ is a mass variations due (for example) to earthquake, and $\delta M^{\text {Others }}$ contains mass changes from Glacial Isostastic Adjustment (GIA), subsurface solid Earth, atmospheric mass changes or other sources of mass transfer which has been corrected in the GRACE observations of level-2. 
Since the GRACE satellite can only sense the total mass variation due to all possible sources, the extraction of individual signals from GRACE observations needs the elimination of other impacts such as GIA, subsurface solid Earth, atmospheric mass changes which among them, the hydrological and oceanic signals have prominent contributions and their amplitudes are significant in the GRACE data.

If one considers the monthly level-2 data of the GRACE in terms of Stokes coefficients, by referring to Eq. 2, the potential changes in this period and at the Earth surface $(R \approx r)$ (see Wahr et al. 1998) can be computed as:

$$
\Delta V=\frac{G M}{R} \sum_{n=2}^{\infty} \sum_{m=0}^{n}\left[\Delta \bar{C}_{m n} \bar{P}_{m n}(\sin \varphi) \cos m \lambda+\Delta \bar{S}_{m n} \bar{P}_{m n}(\sin \varphi) \sin m \lambda\right] .
$$

where $\Delta V$ is the potential change which has been represented in terms of variations in Stokes coefficients, namely $\Delta \bar{C}_{m n}$ and $\Delta \bar{S}_{m n}$. This potential change or equivalently its corresponding differential coefficients $\left(\Delta \bar{C}_{m n}\right.$ and $\left.\Delta \bar{S}_{m n}\right)$ is related to $\delta M^{\mathrm{GRACE}}$ in Eq. 3. Since the gravity acceleration is the gradient of potential, in the spherical coordinate system we have:

$$
\mathbf{g}=\frac{1}{r \cos \varphi} \frac{\partial V}{\partial \lambda} \mathbf{e}_{\lambda}+\frac{1}{r} \frac{\partial V}{\partial \varphi} \mathbf{e}_{\varphi}+\frac{\partial V}{\partial r} \mathbf{e}_{r} .
$$

in which $\mathbf{g}$ is the gravity acceleration and $\mathbf{e}_{\lambda}, \mathbf{e}_{\varphi}$, and $\mathbf{e}_{r}$ are the unit vectors in the longitude, latitude, and radial directions. Therefore, the computation of gravity changes needs the first derivatives of $\Delta V$ as:

$$
\begin{aligned}
& \Delta V_{r}=\left.\frac{\partial \Delta V}{\partial r}\right|_{r \approx R}=-\left(\frac{G M}{R^{2}}\right) \sum_{n=2}^{\infty} \sum_{m=0}^{n}(\mathrm{n}+1)\left[\Delta \bar{C}_{m n} \bar{P}_{m n}(\sin \varphi) \cos m \lambda+\Delta \bar{S}_{m n} \bar{P}_{m n}(\sin \varphi) \sin m \lambda\right] \\
& \Delta V_{\varphi}=\left.\frac{\partial \Delta V}{\partial \varphi}\right|_{r \approx R}=\left(\frac{G M}{R}\right) \sum_{n=2}^{\infty} \sum_{m=0}^{n}\left[\Delta \bar{C}_{m n} \bar{P}_{m n}^{\prime}(\sin \varphi) \cos m \lambda+\Delta \bar{S}_{m n} \bar{P}_{m n}^{\prime}(\sin \varphi) \sin m \lambda\right] \\
& \Delta V_{\lambda}=\left.\frac{\partial \Delta V}{\partial \lambda}\right|_{r \approx R}=\left(\frac{G M}{R}\right) \sum_{n=2}^{\infty} \sum_{m=0}^{n} m\left[-\Delta \bar{C}_{m n} \bar{P}_{m n}(\sin \varphi) \sin m \lambda+\Delta \bar{S}_{m n} \bar{P}_{m n}(\sin \varphi) \cos m \lambda\right] .
\end{aligned}
$$

Since we are interested in the local change, the local Cartesian coordinate with North-East-Down (NED) frame (Eshagh 2010, Eshagh and Abdollahzadeh 2010, 2012; Eshagh et al. 2013) at a point in the Earth surface is introduced in such a way that the $x$-axis is directed to the north, the $y$-axis to the east, and the $z$-axis downwards; therefore, in this local coordinates we have: 


$$
g_{x}=\Delta V_{x}=-\frac{1}{r} \Delta V_{\varphi}, \quad g_{y}=\Delta V_{y}=\frac{1}{r \cos \varphi} \Delta V_{\lambda}, \quad g_{z}=\Delta V_{z}=\Delta V_{r} .
$$

The components of gravity gradient tensor may be expressed as:

$$
\begin{array}{ll}
\Delta V_{x x}=\frac{1}{r} \Delta V_{r}+\frac{1}{r^{2}} \Delta V_{\varphi \varphi}, & \Delta V_{x y}=\frac{1}{r^{2} \cos \varphi} \Delta V_{\varphi \lambda}+\frac{\sin \varphi}{r^{2} \cos ^{2} \varphi} \Delta V_{\lambda} \\
\Delta V_{x z}=\frac{1}{r^{2}} \Delta V_{\varphi}-\frac{1}{r} \Delta V_{r \varphi}, & \Delta V_{y y}=\frac{1}{r} \Delta V_{r}+\frac{1}{r^{2} \cot \varphi} \Delta V_{\varphi}+\frac{1}{r^{2} \cos ^{2} \varphi} \Delta V_{\lambda \lambda} \\
\Delta V_{y z}=\frac{1}{r \cos \varphi} \Delta V_{r \lambda}-\frac{1}{r^{2} \cos \varphi} \Delta V_{\lambda}, & \Delta V_{z z}=\Delta V_{r r} .
\end{array}
$$

in which at the surface of the Earth we have (see also formulas in: Wang et al. 2012, Eshagh 2010, Eshagh and Abdollahzadeh 2010, 2012):

$$
\begin{aligned}
& \Delta V_{r r}=\frac{G M}{R^{3}} \sum_{n=2}^{60}(n+1)(n+2) \sum_{m=0}^{n}\left(\Delta \bar{C}_{n m} \cos m \lambda+\Delta \bar{S}_{n m} \sin m \lambda\right) \bar{P}_{n m}(\sin \varphi) \\
& \Delta V_{\varphi \varphi}=\frac{G M}{R} \sum_{n=2}^{60} \sum_{m=0}^{n}\left(\Delta \bar{C}_{n m} \cos m \lambda+\Delta \bar{S}_{n m} \sin m \lambda\right) \bar{P}_{n m}^{\prime \prime}(\sin \varphi) \\
& \Delta V_{\lambda \lambda}=-\frac{G M}{R} \sum_{n=2}^{60} \sum_{m=0}^{n} m^{2}\left(\Delta \bar{C}_{n m} \cos m \lambda+\Delta \bar{S}_{n m} \sin m \lambda\right) \bar{P}_{n m}(\sin \varphi) \\
& \Delta V_{r \lambda}=-\frac{G M}{R^{2}} \sum_{n=2}^{60} \sum_{m=0}^{n} m\left(-\Delta \bar{C}_{n m} \sin m \lambda+\Delta \bar{S}_{n m} \cos m \lambda\right) \bar{P}_{n m}(\sin \varphi) \\
& \Delta V_{r \varphi}=-\frac{G M}{R^{2}} \sum_{n=2}^{60}(n+1) \sum_{m=0}^{n}\left(\Delta \bar{C}_{n m} \cos m \lambda+\Delta \bar{S}_{n m} \sin m \lambda\right) \bar{P}_{n m}^{\prime}(\sin \varphi) \\
& \Delta V_{\varphi \lambda}=\frac{G M}{R} \sum_{n=2}^{60} \sum_{m=0}^{n} m\left(-\Delta \bar{C}_{n m} \sin m \lambda+\Delta \bar{S}_{n m} \cos m \lambda\right) \bar{P}_{n m}^{\prime}(\sin \varphi)
\end{aligned}
$$

\section{COMPUTATIONAL PROCEDURE AND NUMERICAL RESULTS}

In this section, the scheme to correct the hydrological and oceanic effects from GRACE data of level-2 is presented. The process could be summarized as a following flowchart in Fig. 1.

\subsection{GLDAS model and mass transfer in land}

With reference to Fig. 1, it is seen that the correction of hydrological effects in lands is done with the help of GLDAS model. It was developed jointly at the National Aeronautics and Space Administration (NASA) Goddard Space Flight Center (GSFC) and the National Oceanic and Atmospheric Administration (NOAA) National Centers for Environmental Prediction (NCEP) (Rodell et al. 2004). 


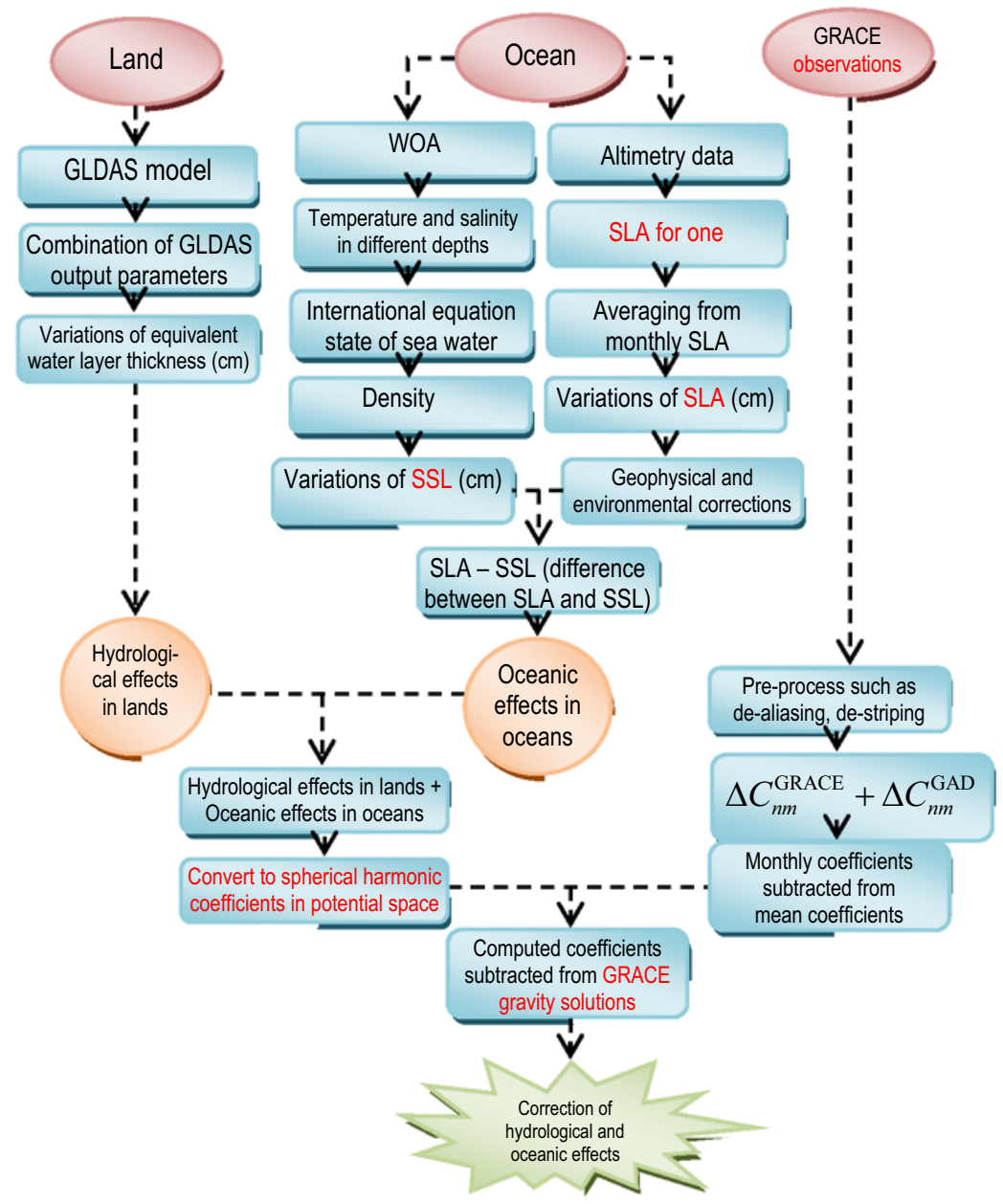

Fig. 1. The technical flowchart of correcting hydrological and oceanic effects from the GRACE data to reveal earthquake signals.

In this study, we use the outputs of the GLDAS model that are combinations of all the affective parameters including average layer soil moisture $(0-200 \mathrm{~cm})$, average layer soil temperature $(0-200 \mathrm{~cm})$, average surface temperature, ground heat flux, snowfall rate, total canopy water storage, surface runoff, snowmelt and snow water equivalent which are computed in terms of variations in water layer thickness. Since we are interested in the Sumatra earthquake occurred on 26 December 2004, to evaluate the hydrological effects at this epoch, the difference between water layer thickness in January 2005 and its mean value from January 2003 to December 2006 covering 47 months, is computed. 
It is worth to mentioned that in spite of a number of analyses and assessment which have shown that the GLDAS could model the complete global hydrological variations in reasonable manner (see, e.g., Jin et al. 2012) some other showed how well and often how poorly GLDAS and other models fit to the GRACE data (see Sneeuw et al. 2014, Lorenz et al. 2014).

\subsection{Oceanic mass transfer from WOA and satellite altimetry}

In the oceans, there are two important factors that cause the variations of water level. One of them is due to raining, evaporation, river discharge and ice sheet melting known as sea level anomaly and the other is due to water becoming warmer or (less) salty. The second effect is referred to as steric component and the first is known as non-steric component.

To correct oceanic effects in oceans, the two sources of variations mentioned above must be collected together as (Chambers 2006a):

$$
\Delta \eta_{\text {Ocean }}(\varphi, \lambda, t)=\Delta \eta_{\mathrm{SLA}}(\varphi, \lambda, t)-\Delta \eta_{\mathrm{SSL}}(\varphi, \lambda, t)
$$

in which $\Delta \eta_{\text {ocean }}$ is the total equivalent water thickness variations in oceans, $\Delta \eta_{\mathrm{SLA}}$ is the sea level anomaly, and $\Delta \eta_{\mathrm{SSL}}$ are the steric sea level variations.

To derive $\Delta \eta_{\text {ocean }}$, we use the WOA model in conjunction with satellite altimetry data. Satellite altimetry could measure the height of the surface of the oceans above the reference ellipsoid (a purely geometric quantity). However, the observed sea surface heights that are measured by satellite altimetry contain both steric and non-steric sea level changes. Steric sea level relates to changes in the structure of atoms in molecule and depends on many factors, the most important being temperature and salinity (Ishii et al. 2006), and could be computed with the aid of WOA model (see following sections).

\subsubsection{Satellite altimetry data}

In this study we use Jason-1 satellite that is a joint project between the NASA (United States) and CNES (The Centre national d'études spatiales) space agencies. The satellite's cycles used here are 110, 111, 112, and 113 cycles. As the case study in this paper focuses on the Sumatra earthquake occurred in December 2004, the oceanic effects must be computed at this period. To do so, we use global sea level anomaly data of January 2005 derived from Jason-1 altimetry mission which shows the variation in the sea surface height versus mean sea height. The Basic Radar Altimetry Toolbox (BRAT) is a software designed to process radar altimetry data. It has the capability to read all altimetry data from official data centers, do some processing strategies and computations and visualize the results. The sea level data have been corrected for some geophysical and environmental effects, such as sea state bias, ionospheric delay, dry and wet tropospheric corrections, tide effects 
(ocean tides, pole tide), ocean tide loading, electromagnetic bias and inverse barometer correction (Ducet et al. 2000).

\subsubsection{World Ocean Atlas model}

The World Ocean Atlas (WOA) is a model produced by the Ocean Climate Laboratory of the National Oceanographic Data Center (U.S.). The WOA dataset provides eight oceanographic variables such as: ocean temperature and salinity, dissolved oxygen, apparent oxygen utilization, percent of oxygen saturation, phosphate, silicic acid, and nitrate. The most important data set of the WOA consists of monthly $1^{\circ}$ grid points of temperature and salinity down to $1500 \mathrm{~m}$. The temperature and salinity, with the aid of International Equation state of Sea Water (IES) (Jayne et al. 2003), are used to compute density distribution of oceans water in different depths. We compute the difference between density in January 2005 consisting of 26 columns (depths from 0 to $1500 \mathrm{~m}$ ) and the mean density (computed by averaging over one year) consisting of 35 columns (depths from 0 to $3500 \mathrm{~m}$ ) and divide to standard density of water $\left(\rho_{0}=1027 \mathrm{~kg} / \mathrm{m}^{3}\right)$. By integrating this density difference over the water column (along the depth) from depth 0 to $1500 \mathrm{~m}$ (temperature and salinity variations after this depth are slow and can be neglected for practical purposes) the steric sea level variations for $1^{\circ} \times 1^{\circ}$ grid are derived as (Chambers 2006b):

$$
\Delta \eta_{\mathrm{SSL}}(\varphi, \lambda, t)=\frac{1}{\rho_{0}} \int_{-h}^{\text {surface }}[\rho(\varphi, \lambda, t, z, T, S)-\bar{\rho}(\varphi, \lambda, t, z, \bar{T}, \bar{S})] d z .
$$

In Eq. $11, \Delta \eta_{\mathrm{SLL}}$ is the equivalent water thickness changes for steric sea level, $\rho_{0}$ is the standard density of water, $h$ is $1500 \mathrm{~m}, \rho$ is the density and is a function of latitude, longitude, time $(t)$, depth $(z)$, temperature $(T)$ and salinity $(S)$, and $\bar{\rho}$ is mean density function.

\subsection{GRACE data}

The geopotential coefficients of monthly gravity data of level-2 computed by Center Space Research (CSR05) have been used in this research. These coefficients have been fully normalized to degree and order 60, corresponding to the spatial resolution of $300 \mathrm{~km}$ and above (Tapley et al. 2004).

In this study, we use some of the monthly average GRACE gravity solutions between the periods of January 2003 to December 2006 which includes 47 months. We subtract the value of $\bar{C}_{n m}$ and $\bar{S}_{n m}$ in January 2005, from the mean value of these coefficients over time range of January 2003 to December 2006 to evaluate global mass change due to Sumatra earthquake occurred on 26 December 2004 (see Fig. 1). 
The impact of atmosphere as well as short-period (periods less than 1 month) ocean and atmospheric signals appearing in the GRACE monthly solutions have been removed from data of level-2 (Tapley et al. 2004). Since GRACE samples the Earth with a complicated temporal and spatial pattern during each month, the short-period signals don't get completely averaged out (Elsaka 2014). To minimize these effects, models of the ocean and atmosphere are used to remove their effects from the raw data, before constructing the monthly gravity field solutions. Also, to remove spatial correlation in the GRACE data, we use Gaussian filter with radius of $350 \mathrm{~km}$ (Wahr et al. 1998) which is necessary to reveal the fine pattern caused by the earthquake. Besides the errors in the orbit determination, measurements from various onboard instruments and the so-called de-aliasing background models, there are geographically correlated high-frequency errors in the GRACE temporal gravity solutions, so the pre-processing in the GRACE data is necessary to reveal the fine pattern caused by the earthquake.

\subsection{Correction of GRACE data of level-2}

Having introduced the required data set and models, in this sub-section we summarize the overall approach for reduction of hydrological and oceanic signals from the GRACE observations of level-2. Consequently, variations of total hydrological and oceanic effects in January 2005 could be computed by combination of hydrological and oceanic effects in lands and oceans as:

$$
\Delta_{\text {Hydrological }}^{\text {Oceanic }}(\varphi, \lambda, t)=\Delta \eta_{\mathrm{GLDAS}}(\varphi, \lambda, t)+\Delta \eta_{\text {Ocean }}(\varphi, \lambda, t) .
$$

According to Eq. 12, the total oceanic and hydrological signals in oceans and lands are computed in terms of equivalent water thickness. To derive the mass variations and gravity changes due to these effects, we must convert the results that are in terms of water layer thickness to gravity space $\left(\Delta^{\text {Gravity }}(\varphi, \lambda, t)\right)$ using the so-called Love number (Wahr et al. 1998, Agnew 2007).

$$
\Delta^{\text {Gravity }}(\varphi, \lambda, t)=\left(\frac{1+k_{n}}{2 n+1} \times \frac{3 \rho_{w}}{a \rho_{E}}\right) \times \Delta_{\text {Hydrology }}^{\text {Oceanic }}(\varphi, \lambda, t) .
$$

In Eq. 13, $k_{n}$ is the second Love number defined as the cubical dilation or the ratio of an additional potential (self-reactive force) produced by the deformation of the deforming potential (Agnew 2007). In addition, $\rho_{w}$ is the average density of water $\left(1027 \mathrm{~kg} / \mathrm{m}^{3}\right), \rho_{\mathrm{E}}$ the average density of the Earth $\left(5517 \mathrm{~kg} / \mathrm{m}^{3}\right), a$ the mean radius of the Earth and $n$ is the degree in spherical harmonics.

Ultimately to reduce the effects of gravity changes due to hydrological and oceanic impacts from the GRACE measurements of level-2, it is neces- 
sary that $\Delta^{\text {Gravity }}(\varphi, \lambda, t)$ is represented by series expansion in terms of orthogonal spherical harmonic as:

$$
\Delta^{\text {Gravity }}(\varphi, \lambda, t)=\sum_{n=2}^{\infty} \sum_{m=0}^{n}\left[\Delta \bar{C}_{m n} \bar{Y}_{n m}^{C}(\varphi, \lambda)+\Delta \bar{S}_{m n} \bar{Y}_{n m}^{S}(\varphi, \lambda)\right]
$$

in which $\bar{Y}_{n m}^{C}(\varphi, \lambda)$ and $\bar{Y}_{n m}^{S}(\varphi, \lambda)$ are defined as:

$$
\left\{\begin{array}{l}
\bar{Y}_{n m}^{s}(\varphi, \lambda) \\
\bar{Y}_{n m}^{C}(\varphi, \lambda)
\end{array}=\bar{P}_{m n}(\sin \varphi)\left\{\begin{array}{l}
\sin m \lambda \\
\cos m \lambda
\end{array} .\right.\right.
$$

In Eq. 14, $\Delta \bar{C}_{m n}$ and $\Delta \bar{S}_{m n}$ are corresponding expansion coefficients and could be determined as:

$$
\begin{aligned}
& \Delta \bar{C}_{m n}=\frac{1}{H^{*}} \iint_{\sigma} \Delta^{\text {Gravity }}(\phi, \lambda, t) \bar{Y}_{n m}^{C}(\varphi, \lambda) d S, \\
& \Delta \bar{S}_{m n}=\frac{1}{H^{*}} \iint_{\sigma} \Delta^{\text {Gravity }}(\phi, \lambda, t) \bar{Y}_{n m}^{S}(\varphi, \lambda) d S,
\end{aligned}
$$

where $H^{*}$ is the norm of spherical harmonic defined by:

$$
\begin{aligned}
& H^{*}=\frac{2 \pi}{2 n+1} \frac{(n+m) !}{(n-m) !}, \quad m \neq 0 \\
& H^{*}=\frac{4 \pi}{2 n+1}, \quad m=0 .
\end{aligned}
$$

It is necessary to mention that in the process of recovery of spherical harmonic coefficients of level-2 data, they are corrected for the effects of oceanic signals, known as background ocean model. Thus, to have a correct evaluation of oceanic signal in the GRACE data, we should restore the background ocean model as:

$$
\Delta C_{n m}^{T}(t)=\Delta C_{n m}^{\mathrm{GRACE}}(t)+\Delta C_{n m}^{\mathrm{GAD}}(t)
$$

where $\Delta C_{n m}^{\mathrm{GAD}}$ are pressure variations based entirely on an ocean model (see Flechtner 2007) and $\Delta C_{n m}^{\mathrm{GRACE}}$ are coefficients of monthly gravity data of level-2.

\section{CASE STUDY}

Having discussed the general procedure for reduction of hydrological and oceanic effects, in this section we illustrate the performance of proposed strategy. For the case study, we choose the active tectonic region of Sumatra to predict the co-seismic gravitational gradient changes which stricken by 
9.2 magnitude earthquake at Sunday on 26 December 2004 at 00:58:53 UTC with fault zone that is located at $3.316^{\circ} \mathrm{N}, 95.854^{\circ} \mathrm{E}$, with a focal depth of about $30 \mathrm{~km}$. The model consists of 7 sub-fault planes which were determined from seismic records. For convenience, the 7 sub-faults were merged into 3 segments and named Andaman, Nicobar, and Sumatra, respectively. Figure 2 shows the fault planes.

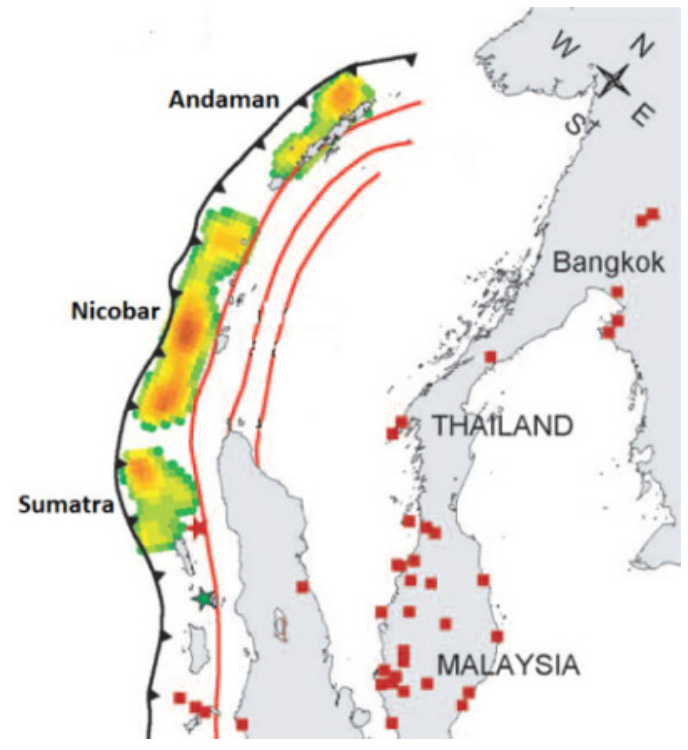

Fig. 2. Finite fault model of segments of Andaman, Nicobar, and Sumatra.

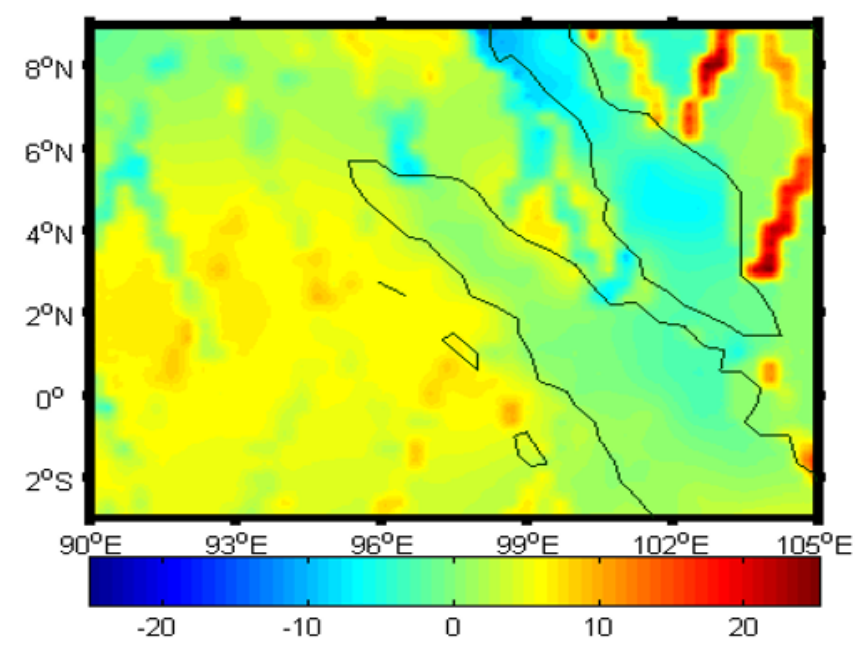

Fig. 3. Variations of hydrological and oceanic effects in January 2005 (in units of $\mathrm{cm}$ ). 
Figure 3 shows the total water layer thickness variations in lands and oceans computed from Eq. 11. All mass changes occurred in a time around December and January but the strongest signals are due to the annual cycle which shows maxima and minima dependent on the seasons and locations which alter from place to place, e.g., between the northern and southern hemisphere. As could be seen in this figure, total water variations in the north of Sumatra and Nicobar segments have negative values which could be a result of sparse vegetation of the region, the larger evaporation and human agricultural irrigation and over-exploitation of groundwater that lead to wastage of groundwater resources.

After combining hydrological and oceanic signals, their effects on gravity variations may be determined. In Fig. 4, hydrological and oceanic effects on gravity field variations have been shown in radial, northwards and eastwards directions in January 2005. These variations could be determined from Eq. 6, considering the $\bar{C}_{n m}$ and $\bar{S}_{n m}$ in Eqs. 14 and 16. As could be seen, the maximum and minimum values of these effects are $3 \mu \mathrm{Gal}$ in radial direction and $-5 \mu \mathrm{Gal}$ in northward direction. As a result from all of the observed gravity variations in this region, the maximum and minimum variations of 5 and $-5 \mu \mathrm{Gal}$ relate to hydrological and oceanic effects which have been corrected in order to obtained tectonic signal in this region.

Here we compute the gravitational gradient changes (see Eq. 8) and use it to discuss the co-seismic deformation resulting from the Sumatra earthquake. Figure 5 shows the gravitational gradient changes components, such

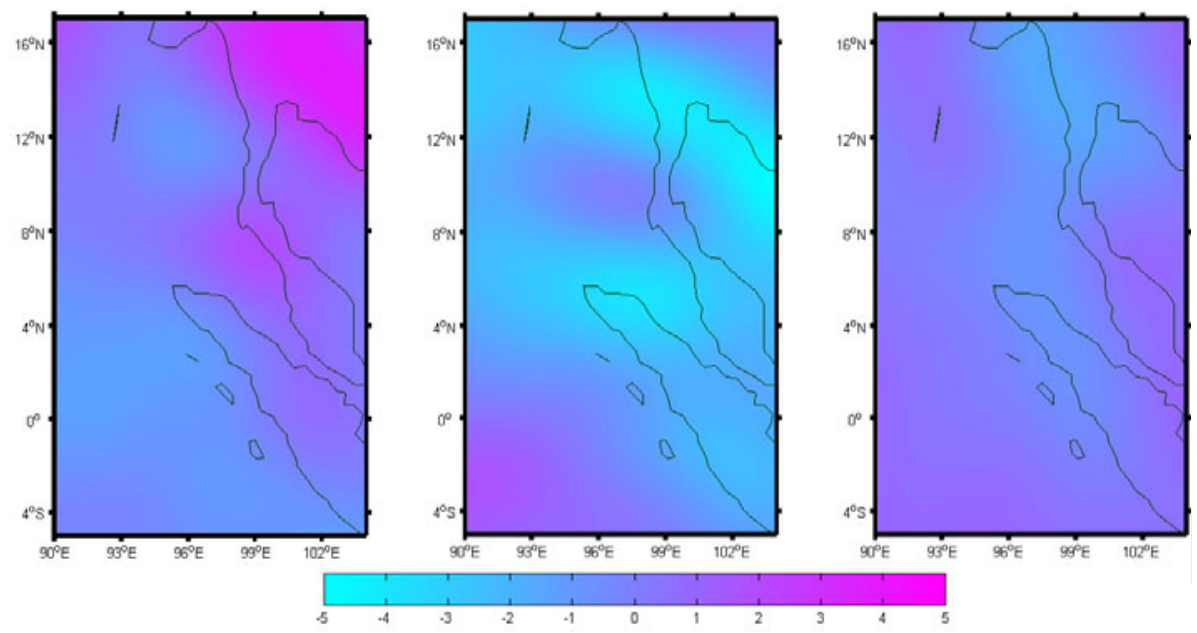

Fig. 4. Variations of hydrological and oceanic signals on gravity changes in January 2005 (in units of $\mu \mathrm{Gal}$ ) in radial direction (a), northward direction (b), and eastward direction (c). 
(a)

(b)

(c)
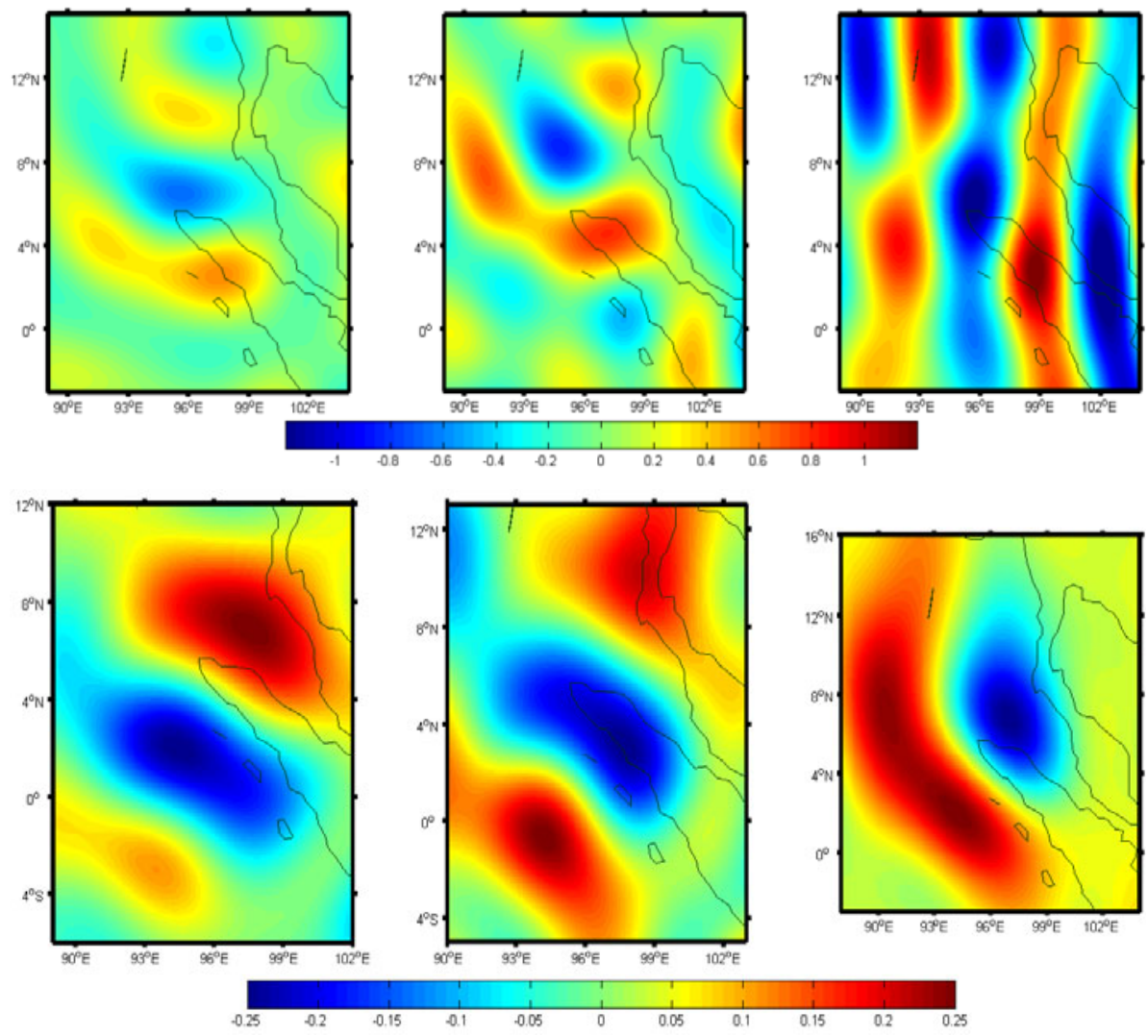

Fig. 5. Gravitational gradient changes components (in units of $\mathrm{mE}$ ) $\Delta V_{x x}$ (a), $\Delta V_{x z}$ (b), and $\Delta V_{z z}$ (c) before correction of hydrological and oceanic effects (top figures) and after these corrections (down figures).

as $\Delta V_{x x}, \Delta V_{x z}$, and $\Delta V_{z z}$, before and after correction of hydrological and oceanic effects. Since the high-frequency contents in gravitational field variation can be amplified by deriving the gravitational gradients, the GRACEderived co-seismic gravitational gradient changes clearly delineate the fault line, locate significant slips, better define the extent of the co-seismic deformation and reveal refined mass redistribution features caused by the earthquake (see Wang et al. 2012).

\section{CONCLUSIONS}

The method for correction of hydrological and oceanic effects from GRACE (the Gravity Recovery and Climate Experiments) data is presented in order to better see the gravity field changes of Sumatra earthquake occurred on 26 
December 2004. The hydrological effects in lands are determined by GLDAS (Global Land Data Assimilation System) model which considers the overall influences of soil moisture, precipitation, snow supply, surface temperature, evaporation, and sensible heat flux, on the total water variation in lands. In the oceans, we used the satellite altimetry data in conjunction with WOA (World Ocean Atlas) model. The WOA model produces temperature and salinity with which one could derive the water layer density using international equation state water. This density can be converted to water layer thickness known as steric sea level. By subtracting steric sea level from sea level anomaly obtained from satellite altimetry data, the oceanic effects in oceans are determined. Adding these two sources of variations, the total hydrological and oceanic signals in lands and oceans are determined in terms of equivalent water layer thickness and converted to gravity changes using Love number and represented in terms of spherical harmonic coefficients. The maximum and minimum impacts of hydrological and oceanic effects on gravity changes are obtained to be of about $3 \mu \mathrm{Gal}$ in radial direction and $-5 \mu \mathrm{Gal}$ in northwards direction, consistent to other studies. Also the maximum and minimum values of gravitational gradient changes are 0.2 and $-.25 \mathrm{mE}$, as observed in $\Delta V_{z z}$ component.

\section{References}

Agnew, D.C. (2007), Earth tides. In: T.A. Herring (ed.), Treatise on Geophysics: Geodesy, Elsevier, New York, 163-195.

Bao, L.F., A. Piatanesi, Y. Lu, H.T. Hsu, and X.H. Zhou (2005), Sumatra tsunami affects observations by GRACE satellites, Eos Trans. AGU 86, 39, 353356, DOI: 10.1029/2005EO390002.

Chambers, D.P. (2006a), Evaluation of new GRACE time-variable gravity data over the ocean, Geophys. Res. Lett. 33, 17, L17603, DOI: 10.1029/2006GL 027296.

Chambers, D.P. (2006b), Observing seasonal steric sea level variations with GRACE and satellite altimetry, J. Geophys. Res. 111, C3, C03010, DOI: 10.1029/2005JC002914.

Chen, J.L., C.R. Wilson, B.D. Tapley, and S. Grand (2007), GRACE detects coseismic and postseismic deformation from the Sumatra-Andaman earthquake, Geophys. Res. Lett. 34, 13, L13302, DOI: 10.1029/2007GL030356.

Creutzfeldt, B., A. Güntner, H. Wziontek, and B. Merz (2010), Reducing local hydrology from high-precision gravity measurements: a lysimeter-based approach, Geophys. J. Int. 183, 1, 178-187, DOI: 10.1111/j.1365-246X.2010. 04742.x. 
Ducet, N., P.Y. Le Traon, and G. Reverdin (2000), Global high-resolution mapping of ocean circulation from TOPEX/Poseidon and ERS-1 and -2, J. Geophys. Res. 105, C8, 19477-19498, DOI: 10.1029/2000JC900063.

Elsaka, B. (2014), Sub-monthly gravity field recovery from simulated multiGRACE mission type, Acta Geophys. 62, 1, 241-258, DOI: 10.2478/ s11600-013-0170-9.

Eshagh, M. (2010), Alternative expressions for gravity gradients in local northoriented frame and tensor spherical harmonics, Acta Geophys. 58, 2, 215 243, DOI: 10.2478/s11600-009-0048-z.

Eshagh, M., and M. Abdollahzadeh (2010), Semi-vectorization: an efficient technique for synthesis and analysis of gravity gradiometry data, Earth Sci. Inform. 3, 3, 149-158, DOI: 10.1007/s12145-010-0062-3.

Eshagh, M., and M. Abdollahzadeh (2012), Software for generating gravity gradients using a geopotential model based on an irregular semivectorization algorithm, Comput. Geosci. 39, 152-160, DOI: 10.1016/j.cageo.2011.06.003.

Eshagh, M., J.-M. Lemoine, P. Gegout, and R. Biancale (2013), On regularized time varying gravity field models based on GRACE data and their comparison with hydrological models, Acta Geophys. 61, 1, 1-17, DOI: 10.2478/ s11600-012-0053-5.

Fatolazadeh, F., B. Voosoghi, and M. Raoofian Naeeni (2016), Wavelet and Gaussian approaches for estimation of groundwater variations using GRACE data, Ground Water 54, 1, 74-81, DOI: 10.1011/gwat.12325.

Feng, G., and S. Jin (2012), Global water cycle and climate change signals observed by satellite gravimetry. In: 2012 IEEE Int. Geoscience and Remote Sensing Symposium (IGARSS), 22-27 July 2012, Munich, Germany, 832-835, DOI: 10.1109/IGARSS.2012.6351432.

Flechtner, F. (2007), GRACE 327-750 (GR-GFZ-AOD-0001). AOD1B product description document for product releases 01 to 04, Rev. 3.1, Gravity Recovery and Climate Experiment, GeoForschungszentrum, Potsdam, Germany.

Han, S.-C., R. Riva, J. Sauber, and E. Okal (2013), Source parameter inversion for recent great earthquakes from a decade-long observation of global gravity fields, J. Geophys. Res. 118, 3, 1240-1267, DOI: 10.1002/jgrb.50116.

Heiskanen, W.A., and H. Moritz (1967), Physical Geodesy, W.H. Freeman, San Francisco.

Ishii, M., M. Kimoto, K. Sakamoto, and S.I. Iwasaki (2006), Steric sea level changes estimated from historical ocean subsurface temperature and salinity analyses, J. Oceanogr. 62, 2, 155-170, DOI: 10.1007/s10872-006-0041-y.

Jayne, S.R., J.M. Wahr, and F.O. Bryan (2003), Observing ocean heat content using satellite gravity and altimetry, J. Geophys. Res. 108, C2, 3031, DOI: 10.1029/2002JC001619. 
Jin, S.G., AA.. Hassan, and G.P. Feng (2012), Assessment of terrestrial water contributions to polar motion from GRACE and hydrological models, J. Geodyn. 62, 40-48, DOI: 10.1016/j.jog.2012.01.009.

Lombard, A., D. Garcia, G. Ramillien, A. Cazenave, R. Biancale, J.M. Lemoine, F. Flechtner, R. Schmidt, and M. Ishii (2007), Estimation of steric sea level variations from combined GRACE and Jason-1 data, Earth Planet. Sci. Lett. 254, 1-2, 194-202, DOI: 10.1016/j.epsl.2006.11.035.

Lorenz, C., H. Kunstmann, B. Devaraju, M.J. Tourian, N. Sneeuw, and J. Riegger (2014), Large-scale runoff from landmasses: a global assessment of the closure of the hydrological and atmospheric water balances, J. Hydrometeorol. 15, 6, 2111-2139, DOI: 10.1175/JHM-D-13-0157.1.

Luthcke, S.B., H.J. Zwally, W. Abdalati, D.D. Rowlands, R.D. Ray, R.S. Nerem, F.G., Lemoine, J.J. McCarthy, and D.S. Chinn (2006), Recent Greenland ice mass loss by drainage system from satellite gravimetry observations, Science 314, 5803, 1286-1289, DOI: 10.1126/science.1130776.

Lyard, F., F. Lefevre, T. Letellier, and O. Francis (2006), Modelling the global ocean tides: modern insights from FES2004, Ocean Dynam. 56, 5-6, 394415, DOI: 10.1007/s10236-006-0086-X.

Rajner, M., T. Olszak, J. Rogowski, and J. Walo (2012), The Influence of continental water storage on gravity rates estimates: case study using absolute gravity measurements from area of Lower Silesia, Poland, Acta Geodyn Geomater. 9, 4, 168, 449-455.

Rodell, M., P.R. Houser, U. Jambor, J. Gottschalck, K. Mitchell, C.J. Meng, K. Arsenault, B. Cosgrove, J. Radakovich, M. Bosilovich, J.K. Entin, J.P. Walker, D. Lohmann, and D. Toll (2004), The Global Land Data Assimilation System, Bull. Am. Meteorol. Soc. 85, 3, 381-394, DOI: 10.1175/ BAMS-85-3-381.

Sneeuw, N., C. Lorenz, B. Devaraju, M.J. Tourian, J. Riegger, H. Kunstmann, and A. Bárdossy (2014), Estimating runoff using hydro-geodetic approaches, Surv. Geophys. 35, 6, 1333-1359, DOI: 10.1007/s10712-014-9300-4.

Stephens, C., J.I. Antonov, T.P. Boyer, M.E. Conkright, R.A. Locarnini, T.D. O'Brien, and H.E. Garcia (2002), World Ocean Atlas 2001, Volume 1. Temperature, NOAA Atlas NESDIS 49, U.S. Gov. Print. Off., Washington, D.C.

Tapley, B.D., S. Bettadpur, M. Watkins, and C. Reigber (2004), The gravity recovery and climate experiment: Mission overview and early results, Geophys. Res. Lett. 31, 9, L09607, DOI: 10.1029/2004GL019920.

Tourian, M.J., O. Elmi, Q. Chen, B. Devaraju, S. Roohi, and N. Sneeuw (2015), A spaceborne multisensor approach to monitor the desiccation of Lake Urmia in Iran, Remote Sens. Environ. 156, 349-360, DOI: 10.1016/j.rse. 2014.10.006. 
Tsoulis, D., and K. Patlakis (2014), Spectral assessment of isostatic gravity models against CHAMP, GRACE, GOCE satellite-only and combined gravity models, Acta Geophys. 62, 4, 679-698, DOI: 10.2478/s11600-013-0176-3.

Velicogna, I., and J. Wahr (2006), Measurements of time-variable gravity show mass loss in Antarctica, Science 311, 5768, 1754-1756, DOI: 10.1126/ science. 1123785 .

Wahr, J., M. Molenaar, and F. Bryan (1998), Time variability of the Earth's gravity field: Hydrological and oceanic effects and their possible detection using GRACE, J. Geophys. Res. 103, B12, 30205-30230, DOI: 10.1029/ 98JB02844.

Wahr, J., S. Swenson, V. Zlotnicki, and I. Velicogna (2004), Time-variable gravity from GRACE: First results, Geophys. Res. Lett. 31, 11, L11501, DOI: 10.1029/2004GL019779.

Wang, L., C.K. Shum, and C. Jekeli (2012), Gravitational gradient changes following the 2004 December 26 Sumatra-Andaman earthquake inferred from GRACE, Geophys. J. Int. 191, 3, 1109-1118, DOI: 10.1111/j.1365246X.2012.05674.x.

Received 22 April 2015

Received in revised form 10 July 2015

Accepted 14 July 2015 